\title{
Service conflict identification and resolution for design of product-service offerings
}

\author{
Wenyan Song and Tomohiko Sakao \\ Journal Article
}

\section{Tweet}

N.B.: When citing this work, cite the original article.

Original Publication:

Wenyan Song and Tomohiko Sakao, Service conflict identification and resolution for design of product-service offerings, Computers \&amp; industrial engineering, 2016. 98(), pp.91-101. http://dx.doi.org/10.1016/j.cie.2016.05.019

Copyright: Elsevier

http://www.elsevier.com/

Postprint available at: Linköping University Electronic Press

http://urn.kb.se/resolve?urn=urn:nbn:se:liu:diva-128270

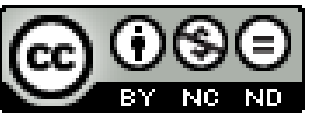




\title{
Service conflict identification and resolution for design of product-service offerings
}

\begin{abstract}
Many manufacturers today are striving to provide high value-added productservice offerings (PSO) to their customers. PSO has heterogonous structure and various requirements, which may lead to technical attributes' conflicts during the design process. The conflicts will lead to the difficulty of concept generation, increase of service delivery failure, and eventually the decrease of customer satisfaction. However, the conflicts in PSO design areas are more intangible and harder to formulate. Moreover, those conflicts are often resolved with trial and error methods in ad hoc processes, which largely depend on the designer's intuition. Thus, in this paper, the authors propose a systematic method to identify PSO design conflicts and resolve them. The proposed method is based on the approach of service function and attributes analysis, group decision making with unbalanced linguistic label set and TRIZ methodology. In addition, a case study of design conflict identification and resolution for elevator service reveals the feasibility and potentials of the proposed method.
\end{abstract}

Key words: Service Function and Attribute Analysis (SFAA), Design Conflict Identification, Design Conflict Resolution, Product/Service System (PSS).

\section{Introduction}

Most manufacturers today are implementing servitization strategy due to increasing competition and environmental concerns(Baines et al. 2009; Geng et al. 2010; Yang et al. 2009). They provide customers with high value-added product-service offerings (PSO) (Sakao \& Shimomura 2007; Song et al. 2015a; Song et al. 2015b; Lee et al .2015). The PSO solutions mainly contain industrial services based on the product, such as product support, repair, maintenance, and upgrading and recycling, etc. PSO design is one of the most important elements to the success of PSO solutions (Aurich et al. 2006).However, in PSO design process, improvement or enhancement of one service attribute may cause the deterioration of another. Then, it can be considered that conflict exists between the two service attributes. For example, self-service attribute can enhance customer convenience, but it reduces the direct interactions between service provider and its customers, and therefore, it may undermine customer perception and experience. Another example is that enhancement of response speed often needs to increase investment in service infrastructure and personnel. Technical conflicts are conflicts between two or more functional attributes of a PSO. The PSO design conflict will lead to the difficulty of the design task, failure rate increase in the delivery phase, and eventually the decrease of customer satisfaction. Especially, in designing service attributes in industry, design is often carried out in an unsystematic manner. Conflict will be among the most troublesome problems obstructing the road for new PSO concept generation. In this respect, design conflict identification and resolution is critical to the success of PSO.

However, the current research largely depends on heuristic methods in identifying 
conflicts. In industry, designers often use tentative rules (e.g., design reviews, change memos, and mock-ups (Klein 2000)) to resolve design conflicts. Furthermore, different with physical products, PSO has the features of stakeholder interaction, heterogeneity, and service intangibility, etc (Váncza et al. 2011; Song et al. 2015c). The conflict between service attributes of PSO is more difficult to be identified. The service attributes conflicts in PSO design areas are more intangible and harder to formulate. These contradictions are often uncertain conflicts between two design parameters. Even though some conflicts are identified by designers, they are often resolved with trial and error methods in ad hoc processes. The service attributes conflicts resolution in PSO largely depends on the designer's experience and intuition. This will heavily influence the quality and efficiency of PSO design.

Therefore, in this paper, the authors propose a systematic method for service attribute conflict identification and resolution for PSO design. The proposed method consists of three successive phases, i.e. 1) service function and attribute analysis, 2) service attribute conflict identification in PSO, and 3) service attribute conflict resolution for PSO design. Using a method to identify and resolve product design conflict is not necessarily novel, but providing a systematic method for PSO design conflict identification and resolution is rarely to be seen in previously academic works. The proposed method is expected to enhance the quality and efficiency of PSO design.

The rest of this paper is organized as follows: Section 2 reviews literature on design conflict identification and resolution; Section 3 provides the new systematic method for PSO design conflict identification and resolution. In Section 4, an industrial case of design conflict identification and resolution for elevator service is presented to illustrate the feasibility and potentials of the proposed method. A discussion of the proposed method is made in Section 5. Conclusions and future research suggestions are presented in Section 6.

\section{Literature review}

\subsection{Design conflict identification}

Due to multi-actors interaction, conflicts can emerge from disagreements between designers about proposed designs (Ouertani 2008). Blackhurst et al. (2008) believe that the conflict can degrade the performance of the system as a whole if not handled effectively. Besides, conflict is a simple and effective mode of problem expression, revealing unsolved inventive challenges (Cavallucci et al. 2009). Thus, the ability to discover conflicts would be a valuable asset, particularly if the discovery occurred proactively. Some researchers have explored the design conflict identification approaches.

Kim et al. (2013) propose a method to detect conflicts, which may occur during the execution time of composite web services, based on model checking. Yan and Zeng (2011) propose a formal structure which represents conflicts based on the axiomatic theory of design modeling and the recursive object model. These methods do not provide a systematic conflict resolving mechanism. They lack tools considering the features of PSO, e.g. the conflict identification method in Kim et al. (2013) is only 
designed for composite web services. Yan (2013) proposes methods for detecting conflicts and presents a set of general resolution principles, which include modifying resource object, separating conflict relations in time or in space, changing the two competing objects, using optimization methods, and replacing the whole conflict. In addition, Sakao (2007) proposes a method to detect conflict between product requirements by extending Quality Function Deployment as well as to resolve the identified conflicts, which can be applied to environmentally conscious product design (Sakao and Fargnoli, 2010). However, these methods are not suitable to be used in the PSO design conflict resolution due to lack of considering features of PSO design. Chen and Nof (2010) study the performance of a newly developed decentralized conflict and error detection and prediction model over different networks. However, this model is not suitable for PSO design conflict resolving for the lack of systematic process support. Ceroni and Velásquez (2003) describe a particular approach to conflict identification and resolution in collaborative design (Vera et al.1998) processes. The developed conflict identification and management system allows testing for conflict identification and resolution by providing a collaboration interface for the distributed designers (Krause et al.1994, Lara and Nof 2003).This method lacks systematic analysis of design functions and attributes, which may influence the accuracy of conflict identification. Based on an analysis of conflict nature and conflict-related human behavior in the concurrent engineering design, Jiang and Nevill (2002) develop a computational model for autonomously identifying the conflict cause in the web-based concurrent engineering design environment. This method also lacks systematic process to aid conflict resolving. Lara and Nof (2003) developed a method which provides fast identification of the conflict situation, diagnostics of conflict parameters, access to the conflict information by all conflicting parties and mechanisms for conflict resolution. However, the method is based on social science theories used to solve conflicts of dispersed designers. Beside conflicts of dispersed designers in PSO design, there are also other types of conflicts, such as product element conflict, service element conflict (e.g. conflict between service cost and service response speed), and even conflict between product elements and service elements, etc. In this respect, PSO design conflict is more complex than the dispersed designers' conflict. Therefore, these different types of conflicts make the method in Lara and Nof (2003) difficult to be directly applied into PSO design domain.

\subsection{Design conflict resolution}

To resolve the design conflicts, some methods have been proposed in the past researches. A graph model for conflict resolution is used in Velasquez et al. (2008) to facilitate conflict modeling and analysis. Hisarciklilar et al. (2010) describe a conflict management approach that lead to the computer-aided management of the product specification conflicts that happen due to the integration of subsystems. Li and Ruan (2002) put forward an integration-based conflict resolution system to manage and resolve conflict in a life cycle way. A hierarchical constraint network is used to detect conflict, and the knowledge-based method is used for knowledge conflicts and schema conflicts, while constraint relaxation is used for data conflicts. Lee et al. (2005) propose 
a conflict resolution method based on case-based reasoning (CBR) approach which helps to resolve some conflicts easily based on the previous resolved similar cases. A major advantage of these methods is the high efficiency of detection if a conflict similar to the problem under consideration is already defined. However, if a new type of conflicts emerges that are different from the predefined conflict types, those methods may fail to identify them. To quickly coordinate conflicts in product performance design, Zhao et al. (2013) propose a transformation bridge method. However, the method requires the designer to have some knowledge of Extension Theory. The designer has to grasp knowledge of extension model, affair-element analysis and extension transformation, which will increase the burden on the designer. Therefore, it is difficult for the designer to use to resolve conflicts in real practice in industry. Considering that consensus can be used for working out an agreement during design conflict resolution, Ostrosi et al. (2012) introduce an approach for consensus modeling in collaborative design (Vera et al. 1998) and distributed design (Krause et al. 1994). Shimomura and Hara (2010) provide a methodology to enable designers to determine the existing conflicts in design solutions and obtain the basic strategies to solve them. Lexical expressions of functions and the ranges of design parameters are used to detect conflicts and TRIZ methodology are used to solve conflict problems. Although the use of TRIZ methodologies makes it possible to solve the design conflicts without unsystematic trial and error, this research does not consider much about the designers' knowledge and experience in the process of conflict identification.

In fact, TRIZ is a well-known methodology for the detection and resolution of conflicts in the product design field. It is created on the basis of the analysis of millions of patents. Contradiction matrix (Mann and Domb 1999) in TRIZ suggests the principles to solve conflicts between elements in a design solution. Rovida et al. (2009) explore the possibility of utilizing the Theory of Inventor's Problem Solving (TRIZ) in the development of product-service combinations. But they don't provide a systematic method for service attribute conflict identification. In order to improve product performance in the use situations, Houssin and Coulibaly (2011) propose an innovative approach to eliminate contradictions between productivity and safety. In their approach, adapted methods like TRIZ are used to resolve contradictions. By proposing the concept of “contradiction cloud”, Cavallucci et al. (2011) claim that designers considerably reduce the fuzziness of a contradiction choice prior entering in a solving phase in Inventive Design processes. Zhang et al. (2003) apply some TRIZ tools (e.g., Problem Formulator, 40 inventive principles, and Separation Principles) into resolve the conflictsolving process of service design. Chai et al. (2005) also show the viability of applying TRIZ to services by proposing a new approach to new service design. However, the service function and attribute analysis is ignored, which may influence the success and failure of the entire conflict resolution process. Ruchti and Livotov (2001) modify the 40inventive principles of TRIZ for service design, and they propose new principles by matching the existing principles. However, the lack of service attribute presentation makes it difficult to detect and solve conflicts. Chang and Chen (2004) develop a conflict problem solving CAD software, which integrates TRIZ into the eco-innovation idea. Design engineers can acquire the most feasible solution and inspiration through 
the proposed software. Although this tool solves the conflicts between technology and environment, it is not suitable to be used in the service design domain, because it lacks mechanism of service attribute analysis to systematically identify possible conflicts related to services. In order to resolve contradictions between product and service components, Kim and Yoon (2012) analyze the suitability of applying theory of inventive problem solving (TRIZ) method to PSS by applying the 40 inventive principles to PSS cases. Yang and Xing (2013) examine and reinterpret the original TRIZ principles to suit the characteristics of PSS innovation, and use Contradiction Matrix and Innovative Principles in TRIZ to facilitate innovative concept generation for PSS development. However, the two methods fall short in analyzing the service function and attributes under the influence of external environment and stakeholders.

Current studies are largely based on heuristics and lack a systematic approach. Designers often use tentative rules such as design reviews, change memos, and mockups (Klein 2000) to resolve design conflicts. Some methods of conflict identification and resolution (e.g., case-based reasoning approach in Houssin et al. 2015) need predefined conflicts data. In addition, although some methods (e.g., Houssin and Coulibaly 2011) are effective in solving conflicts in product design domain, they consider less about the features of PSO. Thus, they cannot directly support PSO design conflict identification and resolution.

\section{Conflict identification and resolution for PSO}

\subsection{Overview}

A systematic method of conflict identification and resolution is proposed in this section. The proposed method consists of three phases, i.e., PSO function and technical attribute analysis, PSO design conflict identification, and PSO design conflict resolution (see Figure1). Firstly, based on the analysis of interactions among product, stakeholders and external environments, an approach of Service Function and Attribute Analysis (SFAA) is proposed to present the service attributes of the PSO. Secondly, a method of group decision making based on unbalanced linguistic label set is utilized to identify potential conflicts between different PSO technical attributes. Thirdly, the contradiction matrix and inventive principles in TRIZ methodology is then introduced to resolve the identified design conflicts of PSO. After resolving conflicts, designers will analyze whether the solution of PSO design conflicts bring new functions or not. If yes, they will implement again the process from stage 1 to stage 3 . If not, the whole process is end. The proposed method provides a standard reference process for the conflict identification and resolution of PSO.

Figure1 Technical attributes’ conflict resolution process 


\subsection{Service function and attribute analysis}

In order to analyze the PSO function and technical attribute, a method named Service Function and Attribute Analysis (SFAA) is developed in this section (Figure2) based on the graph of interactors (Maussang et al. 2009) and function hierarchical structure. Different with the method in Maussang et al. (2009), SFAA consider the function decomposition based on function hierarchical structure. In SFAA, PSO can be broken down into some sub-functions, each function can be described by its name and certain service technical attributes. Moreover, SFAA considers both hierarchical and horizontal relationships between functions, which helps to comprehensively elicit specific service technical attributes. The function decomposition is also an interactive process between customers and the service provider which can facilitate the subsequent PSO design, because it helps designers to know more about the customers' task and contributes to accurate expression of service technical attributes. Moreover, different with the modeling scheme proposed by Arai and Shimomura (2004) and further developed by Sakao et al. (2009), interrelations (e.g. dependence relationship and concurrent relationship) between functions are also considered. In this respect, SFAA is a richer presentation tool for PSO, and it is also a tool to describe the attributes of the service functions. The designers could define the PSO with a series of service functions and technical attributes, e.g. service availability, service cost, and response time, etc.

Figure 2 Service Function and Attribute Analysis (SFAA)

SFAA process allows designers to analyze the interactions among product, stakeholders and external environment. Based on this, service functions and service attributes can be acquired. The relationships between service functions and technical attributes are also revealed in SFAA. It can be seen from the figure 2 that customers and other stakeholders interact with each other to perform certain service functions through the product. In order to meet customer requirement of effective and efficient use of product in the whole product lifecycle, stakeholders interact with each other to perform certain service functions. For example, in order to provide reliable and stable compressed air for customers, the compressor manufacture, spare part supplier, and customers should keep interactions to deliver the service performance of "failure warning and diagnosis”. Besides, constrained by the external environment, PSO should also provide certain service functions to adapt to the environment (production environment, ecological environment, and regulatory environment, etc.), such as energy-saving and noise controlling. For instance, installation and commissioning service need to take into account the layout, lighting, humidity and temperature and other environmental conditions of workshop.

Requirements of stakeholders and external environment can then transferred to the specific service functions and technical attributes. Service designers can use service technical attributes to describe certain service function based on some qualitative or 
quantitative features. For example, "quickly access of failure information of product" and "high reliability of failure diagnosis" can be used to describe the service function of product failure diagnosis. With the method of SFAA, the PSO technical attributes can well be defined.

In SFAA, concurrent or dependence relationships between functions will be also identified. Concurrent relationship refers to the relationship between two or more service activities which must be simultaneously implemented. Only all the service activities in parallel are completed, the service function supported by the concurrent service activities can be considered to be performed. Dependence relationship refers to the relationship between two or more service activities which must be executed sequentially. The complementation of the previous service activity is the premise of the next service activity.

\subsection{Service conflict identification in PSO design}

Conflict identification is the critical step of conflict management. There are generally three types of correlations between the technical attributes, namely, positive correlation, irrelevant correlation and negative correlation. Positive correlation indicates that the two technical attributes are mutually reinforcing, and negative correlation indicates that the two technical attributes are mutually conflicting. Each technical attribute needs to be examined to see whether or not it contradicts with some other technical attributes. The concurrent or dependence relationships between functions will help the experts to explore the possible conflicts. Competition for limited service resources or even the same resource may lead to conflicts between service activities with concurrent relationships. While conflicts may also exist between the service activities with dependence relationships, because lack of necessary previous service output will cause the next service activity waiting for inputs.

With the presented relationships between functions in SFAA, the experts can describe and share preliminary judgments on the type of conflict. If concurrent relationship exists between two service functions, conflict identification team would mainly check whether there are resource competition between technical attributes of the concurrent functions, i.e. resource-based conflict. While dependence relationships exists between two service functions, the team would mainly check whether there are chronological contradiction or information lacking between technical attributes of the dependent functions, i.e. process-based conflict. Using SFAA in this manner, early conflict identification is more supported and documented. In industry, conflict identification of PSO technical attributes is carried out essentially as group decision making. Various experts tend to choose linguistic terms with different granularities in judging on the potential conflicts. Indeed, in group decision-making process, decision-makers prefer to use linguistic terms with different granularities to present their judgments (Malakooti 2012). Some experts lacking experience may even use the uncertain linguistic terms with intervals to evaluate the potential conflicts. Therefore, to identify the potential design conflicts of PSO with linguistic terms, it is necessary to unify the linguistic terms with multi-granularity into uniform granularity-based linguistic judgments, and aggregate the linguistic judgments to obtain the comprehensive judgment on the 
potential conflict. The granularity here refers to the number of linguistic terms in a linguistic label set. For example, to assess a service performance, decision-maker A prefer to use the linguistic label set with granularity of $3\{-1=$ extremely poor, $0=$ medium, $1=$ extremely good $\}$, and decision-maker B use the linguistic label set with granularity of $9\{-4=e x t r e m e l y$ poor, $-2=$ very poor, $-1=$ poor, $-0.4=$ slightly poor, $0=$ fair, $0.4=$ slightly good, $1=$ good, $2=$ very good, $4=$ extremely good $\}$. Although both decision-makers A and B provide score of 1 for the service performance, they have different meanings (A considers that the service is extremely good, while B considers that the service is good). Therefore, it is necessary to unify the linguistic terms to avoid unnecessary loss of information.

The conflict identification process of PSO is described as follows:

Step 1: the relationship between different technical attributes $\mathrm{TA}_{j}(j=1,2, \ldots, n)$ is firstly evaluated based on unbalanced linguistic label set $S^{(\mathrm{k})}(\mathrm{Xu} 2009)$.

$$
S^{(\mathrm{k})}=\left\{S_{\beta}^{(k)} \mid \beta=1-\mathrm{k}, 2(2-\mathrm{k}) / 3,2(3-\mathrm{k}) / 4, \ldots, 0, \ldots, 2(\mathrm{k}-3) / 4,2(\mathrm{k}-2) / 3, \mathrm{k}-1\right\}
$$

In equation $1, k$ is a positive integer to be used to calculate linguistic label in the linguistic label set. From equation (1), we can see that the number of linguistic variables in the linguistic label set $S^{(\mathrm{k})}$ is $2 \mathrm{k}-1$. The larger the value of $k$ is, the more linguistic terms in the linguistic label set. $S_{\beta}^{(k)}$ is the linguistic judgment on relationship between PSO technical attributes. $S_{1-k}^{(k)}$ and $S_{k-1}^{(k)}$ represent the upper and lower boundaries of the linguistic label set, respectively. $\beta$ represents the degree of conflict or cooperation relationships between PSO technical attributes; $k$ is an integer which is greater than zero. Different linguistic label sets with different granularities can be acquired by setting different values for $k$. For example, when $k=4$, the granularity of the linguistic label set is 7. Thus, $S^{(4)}=\left\{S_{-3}^{(4)}=\right.$ "strong conflict", $S_{-4 / 3}^{(4)}=$ "medium conflict", $S_{-1 / 2}^{(4)}=$ "weak conflict", $S_{0}^{(4)}=$ "irrelevant", $S_{1 / 2}^{(4)}=$ "weak cooperation", $S_{4 / 3}^{(4)}=$ "medium cooperation" $S_{3}^{(4)}=$ "strong cooperation"\} (see Figure 3), then $\beta=-3$, -4/3, $1 / 2,0,1 / 2,4 / 3$ and 3 , respectively.

Figure 3 Linguistic label set $S^{(4)}$ with granularity of 7

In the design process of PSO, experienced professionals tend to use crisp value to judge the relationships between different technical attributes, while inexperienced design team members tend to use the uncertain linguistic variables with intervals. Thereby, the initial linguistic judgment matrix $M_{c q}$ can be obtained as follows:

$$
M_{c q}=\left(c_{i j q}\right)_{n \times n}(q=1,2, \ldots, l) .
$$

$c_{i j q}$ denotes the $q^{\text {th }}$ expert's judgment on the relationship between the $i^{\text {th }}$ technical attributes and the $j^{\text {th }}$ technical attributes, and $l$ is the number of experts in the design team.

For any linguistic judgment $S_{\beta 1}^{(k)}, S_{\beta 2}^{(k)}$, if $\lambda, \lambda_{1}, \lambda_{2} \in[0,1]$, their operation rules (Wu and Chen 2007) are as follows : 


$$
\begin{gathered}
S_{\beta 1}^{(k)} \oplus S_{\beta 2}^{(k)}=S_{\beta 2}^{(k)} \oplus S_{\beta 1}^{(k)}=S_{\beta 1+\beta 2}^{(k)} \\
\lambda S_{\beta}^{(k)}=S_{\lambda \beta}^{(k)} \\
\left(S_{\beta}^{(k)}\right)^{\lambda}=S_{\beta^{\lambda}}^{(k)} \\
\lambda\left(S_{\beta 1}^{(k)} \oplus S_{\beta 2}^{(k)}\right)=\lambda S_{\beta 2}^{(k)} \oplus \lambda S_{\beta 1}^{(k)}=S_{\lambda(\beta 1+\beta 2)}^{(k)} \\
\left(\lambda_{1}+\lambda_{2}\right) S_{\beta}^{(k)}=\lambda_{1} S_{\beta}^{(k)}+\lambda_{2} S_{\beta}^{(k)}
\end{gathered}
$$

Step 2: the linguistic judgments of experts are derived from the different unbalanced linguistic label sets with different granularities. In order to make the linguistic labels uniform without loss of decision information, it is necessary to unify them into the linguistic judgments with the same granularity. Moreover, the linguistic judgments with the same granularity will facilitate judgments aggregation in decision making of the conflict degree. Then, the granularity transformation functions in Xu (2009) is firstly introduced to unify different unbalanced linguistic label sets with different granularities in a unique linguistic label set.

Assume that $\bar{S}^{\left(k_{1}\right)}=\left\{S_{\beta}^{\left(k_{1}\right)} \mid \beta \in\left[1-\mathrm{k}_{1}, \mathrm{k}_{1}-1\right]\right\}, \bar{S}^{\left(k_{2}\right)}=\left\{S_{\gamma}^{\left(k_{2}\right)} \mid \gamma \in\left[1-\mathrm{k}_{2}, \mathrm{k}_{2}-1\right]\right\}$ are two linguistic label sets with different granularities, respectively, then they can be converted to be each other in accordance with the following formula (Xu 2009):

$$
\begin{aligned}
& F_{k_{1}}^{k_{2}}: S_{\left[1-k_{1}, k_{1}-1\right]}^{\left(k_{1}\right)} \rightarrow S_{\left[1-k_{2}, k_{2}-1\right]}^{\left(k_{2}\right)} \\
& \gamma=F(\beta)=\frac{\beta\left(k_{2}-1\right)}{k_{1}-1}
\end{aligned}
$$

For example, we can use the equation $\gamma=\frac{\beta(4-1)}{3-1}=\frac{3}{2} \beta$, to convert the linguistic label set $S^{(3)}$ into $S^{(4)}$. That is, $S_{-2}^{(3)} \rightarrow S_{-3}^{(4)}, S_{-2 / 3}^{(3)} \rightarrow S_{-1}^{(4)}$, and the like.

Similarly,

$$
\begin{aligned}
& F_{k_{2}}^{k_{1}}: S_{\left[1-k_{2}, k_{2}-1\right]}^{\left(k_{2}\right)} \rightarrow S_{\left[1-k_{1}, k_{1}-1\right]}^{\left(k_{1}\right)} \\
& \beta=\frac{\gamma\left(k_{1}-1\right)}{k_{2}-1}
\end{aligned}
$$

Then the linguistic label set $S^{b}$ utilized by most of experts is considered to be the basic reference linguistic label set. Other linguistic label sets with different granularities can be unified into the reference linguistic label set $S^{b}$ according to the formula (7)-(10). Then, all the linguistic judgments $c_{i j q}$ in the initial linguistic judgment matrix $M_{c q}(q=$ $1,2, \ldots, l)$ can be unified. Direct calculation of the linguistic judgments of technical attributes' relationships is expected to reduce unnecessary loss of information in the decision making process.

From step 3 to step 5,we consider uncertain linguistic judgments of conflicts for the first time, and convert them into crisp judgments to get the aggregated value of individual judgments which denote the conflict degree or cooperation degree, which doesn't appear in past researches.

Step 3: all the uncertain linguistic judgments in the linguistic judgment matrix are converted into the certain ones. For any linguistic judgments with intervals $\left(\mathrm{C}_{i j q}=\left[\mathrm{c}_{i j q}^{L}, \mathrm{c}_{i j q}^{U}\right]\right)$, the coefficient $\xi(0<\xi<1)$ is introduced, then the uncertain linguistic judgments can be converted into crisp ones is as follows:

$$
\mathrm{c}_{i j q}=(1-\xi) \times c_{i j q}^{L}+\xi \times c_{i j q}^{U}
$$

Where $c_{i j q}$ denotes the $q^{\text {th }}$ expert's judgment on the relationship between the $i^{\text {th }}$ technical attribute and the $j^{\text {th }}$ technical attribute; $c_{i j q}{ }^{L}$ and $c_{i j q}{ }^{U}$ represent the upper 
boundary and lower boundary of the uncertain linguistic judgment $c_{i j q}$; $\xi$ represents expert's preference towards the upper boundary and lower boundary, and the value of $\xi$ is generally set as 0.5 to keep a neutral preference.

Then, according to the equation (11), all the elements in the linguistic judgment matrix have been converted to the crisp linguistic judgments with uniform granularities.

The new linguistic judgment matrix is denoted as $\mathrm{M}_{c q}^{a}=\left(\mathrm{c}_{i j q}^{a}\right)_{n \times n} \quad(q=1,2, \ldots, l)$.

Step 4: $\quad$ all the granularity-unified linguistic judgments $\left(\mathrm{c}_{i j q}^{a}\right)$ of different experts are aggregated to get the decision value $\left(c_{i j}^{a}\right)$ of the conflict as follows:

$$
\mathrm{c}_{i j}^{a}=\left[\sum_{1}^{l} c_{i j q}^{a}\right] / l
$$

Where $l$ is the number of decision makers; $i, j=1,2, \ldots, n, q=1,2, \ldots, l$.

Step 5: the potential conflicts are identified with the decision value $\left(c_{i j}^{a}\right)$. If the subscript of $c_{i j}^{a}$ is smaller than 0 , there is a conflict between the $i^{\text {th }}$ PSO technical attribute and the $j^{\text {th }}$ PSO technical attribute. The conflict with lager absolute value of the subscript should be given priority to be resolved.

Because the conflicts only exist between PSO technical attributes that are negatively correlated, the technical attributes judged as positively correlated should not be considered in the aggregation process. In this way, the design conflict identification process can be simplified.

\subsection{Service conflict resolution in PSO design}

In order to resolve the identified conflict, a PSO conflict resolution process based on technical contradiction matrix leveraged from TRIZ is proposed in this section. Details of PSO design conflict resolution process are described as follows:

Step 1: the corresponding TRIZ parameters are identified for the PSO technical attributes.

Typical PSO technical attributes consist of service response, service flexibility, service reliability, service quality, service availability, service efficiency, service resource, service time and service cost, etc. These PSO technical attributes cannot be directly used in TRIZ. Thus, it is necessary to firstly refine and standardize the conflicted PSO technical attributes into TRIZ parameters. The conflicting PSO technical attributes are matched with corresponding TRIZ parameters in the light of their similar connotations. For example, the PSO technical attribute "quick service response " refers to that the service provider responses to customer service requests with relatively high speed, and therefore, this PSO technical attribute can be represented by the TRIZ parameter " 9 . Speed" (The velocity of an object; the rate of a process or action in time). Similarly, other PSO technical attributes can also represented by the corresponding TRIZ parameters.

Step 2: the TRIZ contradiction matrix is examined to find out the corresponding favorable inventive principles.

The identified conflict can be solved by using the contradiction matrix in TRIZ. Firstly, it is necessary to detect the TRIZ parameter which is "feature to improve" in the columns and "undesired result" in the rows. Then, the conflict of PSO technical attribute is resolved by using the recommend inventive principles that are listed in the intersection of the improving and worsening TRIZ parameters. The inventive principles 
are used to inspire the possible conflict resolutions. Some appropriate re-explanations of the traditional 40 TRIZ inventive principles is necessary, because it will make the 40 TRIZ inventive principles adapt to the conflict resolving problems in the field of product service offerings. For example, the invention principle 2 "Extraction (Extracting, Retrieving, Removing)" in the TRIZ is as follows:

a. Extract the "disturbing" part or property from an object.

b. Extract only the necessary part or property from an object.

Based on hints from the "Extraction", design experts can re-explain and adjust the invention principle 2 "Extraction" as follows:

a. Extract the "disturbing” process or task from a product-service offering (e.g. outsourcing)

b. Extract only the key process or task from a product-service offering.

Similarly, other inventive principles can be also well re-explained and adjusted to adapt to its use in domain of PSO.

Step 3: the specific solution for the PSO design conflicts is generated.

Following the recommended principles and suggested ways, design experts can make possible conflict resolutions.

\section{Case study}

To demonstrate how the proposed method of conflict resolution works, we applied it to an actual PSO design case in elevator manufacturing Company M. Elevator Company $\mathrm{M}$ is a leading manufacturer who provides different types of elevators including passenger/freight elevator, hospital elevator, escalator, and elevator monitoring system, etc. Besides, the Company also offers elevator services including installation, maintenance, repair, remote monitoring, elevator upgrading and spare parts supply, etc. Company $\mathrm{M}$ wants to enhance its competitiveness in the elevator service market by improving its service design efficiency.

\subsection{Elevator service function and attribute analysis}

Considering the external environment and stakeholders interactions, method of SFAA proposed in section 3.1 was used to describe the elevator service functions and technical attributes (see Figure 4). Based on the described model, technical attributes of elevator service were listed in Table 1.

Figure 4 Service function and attribute analysis of elevator PSO

Table1

Technical attributes of elevator service

\subsection{Conflict identification for elevator service technical attribute}

Five design experts made judgments on the relationships between different technical 
attributes of elevator service by using unbalanced linguistic label set with different granularity of 7,9 , and 5 . The $1^{\text {st }}$ expert and the $4^{\text {th }}$ experts used uncertain linguistic judgments with intervals to evaluate the relationships between technical attributes, because they lack some experience in elevator service design. The team considered only the pair of technical attributes existing at least one linguistic judgment of negative correlation (see Table 2), because the collective value of judgments may be negative which finally denotes conflicts between technical attributes.

Table 2

The linguistic judgments on the relationships between TAs of elevator service

Unify the linguistic judgments in Table 2 into the linguistic judgments with the same granularity according to the formula (7) to (10). The linguistic label set $S^{(4)}$ was considered to be the basic reference linguistic label set, because it was utilized by most of experts in the design team. The linguistic judgments with uniform granularity of 7 can be seen in Table 3 .

Table 3

The unified linguistic judgments on the relationships between TAs

Then, convert the uncertain linguistic judgments into the certain ones according to the formula (11) $(\xi=0.5)$. After that, aggregate all the granularity-unified linguistic judgments of different experts to get the indication value of the conflict in the light of (12). 
Table 4

The unified linguistic judgments and indication value of conflict

It is clear to be seen from the Table 4 that the indication values of conflict hold the following relation: $S_{-1.7}^{4}<S_{-1.45}^{(4)}<S_{0}^{(4)}<S_{0.2}^{(4)}$. Thus, we can know that TA9 (Wide coverage of service network) conflicts with $\mathrm{TA}_{10}$ (Short time of service dispatching) and $\mathrm{TA}_{3}$ (Wide coverage of condition monitoring) conflicts with $\mathrm{TA}_{4}$ (Accurate failure diagnosis).

\subsection{Conflict resolution of elevator service technical attribute}

Step 1: the corresponding TRIZ parameters were identified for the corresponding service technical attributes $\mathrm{TA}_{3}$ (Wide coverage of condition monitoring), $\mathrm{TA}_{4}$ (Accurate failure diagnosis), $\mathrm{TA}_{9}$ (Wide coverage of service network) and $\mathrm{TA}_{10}$ (Short time of service dispatching).

$\mathrm{TA}_{3}$ (Wide coverage of condition monitoring) was represented by the TRIZ parameter "37. Difficulty of detecting and measuring” (Measuring or monitoring systems that are complex, costly, require much time and labor to set up and use, or that have complex relationships between components or components that interfere with each other all demonstrate "difficulty of detecting and measuring." Increasing cost of measuring to a satisfactory error is also a sign of increased difficulty of measuring).

$\mathrm{TA}_{4}$ (Accurate failure diagnosis) was represented by the TRIZ parameter " 28 . Measurement accuracy" (The closeness of the measured value to the actual value of a property of a system. Reducing the error in a measurement increases the accuracy of the measurement).

$\mathrm{TA}_{9}$ (Wide coverage of service network) was represented by the TRIZ parameter "33. Ease of operation" (Simplicity: The process is NOT easy if it requires a large number of people, large number of steps in the operation, needs special tools, etc. "Hard" processes have low yield and "easy" process have high yield; they are easy to do right).

$\mathrm{TA}_{10}$ (Short time of service dispatching) was represented by the TRIZ parameter "25. Loss of time" (Time is the duration of an activity. Improving the loss of time means reducing the time taken for the activity).

Step 2: the TRIZ contradiction matrix was examined to find out the corresponding favorable inventive principles.

Firstly, the TRIZ parameter " 37 . Difficulty of detecting and measuring" and "33. Ease of operation" were detected as "improving parameter" in the columns, while "28. Measurement accuracy" and "25. Loss of time” were detected as "worsening parameter" in the rows. Then, search through the intersection of the improving and worsening TRIZ parameters in contradiction matrix for the recommend inventive principles. The number of recommend inventive principles for resolving conflict between $\mathrm{TA}_{3}$ (Wide coverage of condition monitoring) and $\mathrm{TA}_{4}$ (Accurate failure diagnosis) is 24,26,28, and 32, respectively. The number of recommend inventive principles for resolving conflict 
between $\mathrm{TA}_{9}$ (Wide coverage of service network) and $\mathrm{TA}_{10}$ (Short time of service dispatching) is 4,10,28, and 34, respectively.

The appropriate re-explanations of the recommend inventive principles are shown in Table 5 to make them adapt to the problems in the field of product service offerings.

Table 5

The recommended principles for resolving TA’ conflicts of elevator service

Step 3: the specific solution for the PSO design conflicts was generated.

Following the recommended principles and suggested ways, design experts can make possible conflict resolutions.

Elevator service designers considered that "Principle 24: Intermediary/Mediator" and "Principle 26: Copying" were suitable to solve the conflict between $\mathrm{TA}_{3}$ (Wide coverage of condition monitoring) and $\mathrm{TA}_{4}$ (Accurate failure diagnosis). Referring to the sub-principle "Use an intermediary carrier article or intermediary process" in "Principle 24: Intermediary/Mediator" and "Replace unavailable, expensive or fragile object with available or inexpensive copies" in "Principle 26: Copying", there was a hint for designers to make full use of use an computer-aided service system to replace the human service, and remote service to replace the field service to enhance the diagnosis efficiency. Thus, elevator service design team proposed a case-based reasoning diagnosis to solve the conflict between $\mathrm{TA}_{3}$ and $\mathrm{TA}_{4}$. The solution is described as follows: First, sensors on the periphery of elevator collected information of floor, running speed, status of door opening and closing, failure of squatting, failure of hoisting, and maintenance status, etc. Then, the information is transmitted to the platform of elevator operation management by communication module of General Packet Radio Service (GPRS). After that, the platform of elevator operation management can acquire the different features of elevator failures by data mining of failure information. The failure feature information is stored in a case library of elevator failure. Once a new problems arises, the elevator operation management platform can quickly search the failure case library to find a similar problem with possible solutions based on the matching of failure features. This is expected to enhance the efficiency and accuracy of failure diagnosis.

The elevator design team decided to select inventive principle 10 (Preliminary action) to solve the identified conflict. According to the sub-principle of the inventive principle 10 (Preliminary action) "Pre-arrange objects such that they can come into action from the most convenient place and without losing time for their delivery,” it was necessary to provide service skill training for works in advance, and keep the service facilities in good condition. More importantly, it is suggested that service scheduling should be optimized to reduce customer waiting time. Here, the core problem is reducing PSO delivery time without affecting the coverage of service network. If the designers interpreted the principle 10 (Preliminary action) into a preventive maintenance, or improving elevator reliability, it cannot essentially resolve 
the targeted conflict between TA9 (Wide coverage of service network) and TA10 (Short time of service dispatching). This is because preventive maintenance, or improving elevator reliability contribute less to solve the core problem (reducing PSO delivery time without affecting the coverage of service network) even though they may keep the elevator in good condition. Based on these analysis and suggestions of '10. Preliminary action', elevator service design team proposed a precise dispatching method to solve the conflict between TA9 (Wide coverage of service network) and TA10 (Short time of service dispatching). The precise dispatching method is described as follows: The CRM (customer relationship management) system, information system of repair and maintenance, call centre, GIS-based positioning system are suggested to be integrated together. The dispatching system in the call center calculates the optimal service path based on geographic information of elevator, suitable service engineers on duty, and service requirements, etc. Then the service engineer is assigned to go to the filed following the optimal service path. A service work order sheet created by the call centre platform is automatically sent to CRM system. The CRM system will automatically send short messages with voice prompts to the service engineer dispatched. After receiving the dispatching message, the service engineer must respond to it within three minutes, or this dispatching message will be directly sent to the manager of service centre. If the manager of service centre does not respond within three minutes, it will be automatically reported to service director of company. If the service engineer cannot accept the service work order due to reasonable reasons, he or she must promptly click the "delegate to others" in the hand-held terminal. Once the service assignment is completed, customers will receive a reminder message from the call centre platform so that they can supervise and prepare for the whole service process. In this way, the time of service dispatching can be shortened on the basis of service route and resources optimization in advance.

After finding the solutions to resolve the conflict, designers analyzed the solutions to decide whether they bring new functions or not. To simplify the description yet maintaining the essence for the method verification, the cycle repeats are not described here.

\subsection{Feedback from the method users}

To evaluate the effectiveness of the conflict detection method, we also conducted interviews and discussions with the method users.

The conflict detection results are consistent with most judgments of experts. In fact, with the increasing intelligence and complexity of the elevator, each elevator produces much information (e.g. failure modes and operating status) of the elevator using and management in different forms, such as image, video, and sound, etc. Furthermore, wide coverage of elevator monitoring means that the service provider must capture, store and analyze many elevators' operation information at the same time, which may lead to information overload. Under the constraints of limited service resource and time, information overload of monitoring may cause the inaccurate failure diagnosis. Thus, the fact that the design team considered that the $\mathrm{TA}_{3}$ (Wide coverage of condition monitoring) conflicted with $\mathrm{TA}_{4}$ (Accurate failure diagnosis) is a proper reflection of 
the real world situations.

In addition, with the geographical expansion of the service scope, it is more convenient for customers to get various elevator services. However, the number of service personnel and service radius are becoming larger, and the service network structure may also become more complex. These will make the service dispatching become more difficult. With limited service resources, expansion of the service range will increase the time of service dispatching, and ultimately lead to increasing of customer waiting time. Thus, the design team's identification of the conflict between $\mathrm{TA}_{9}$ (Wide coverage of service network) and $\mathrm{TA}_{10}$ (Short time of service dispatching) corresponded to the reality.

The two concrete examples above show the proposed method is effective to address the reality. Moreover, the interview's results reflect that the method provides a systematic way for the method users to identify and resolve conflicts between service conflicts in PSO design. Compared with the ad-hoc manner used before in company M, the proposed method in this research enhance the design efficiency of PSO design process.

\section{Discussion}

The proposed method with SFAA provides a more specific representation of a structure of PSO functions and design attributes. Compared with the graph of interactors (Maussang et al. 2009), SFAA can help to decompose a service function hierarchically into its sub-functions or its underlying functions. Interrelations between functions are also considered. In SFAA, both hierarchical and horizontal relationships between PSO functions can be presented, which helps to comprehensively elicit specific service technical attributes. In this respect, the description with SFAA is useful to share the intention and motivation of service functions. This will provide critical inputs for the following process of conflict identification of technical attributes. This also means that application areas of TRIZ-based conflict solving methods are expanded to include PSO.

Conflict identification results shown in the case study illustrate that the group decision making approach with multi-granular uncertain linguistic information is efficient and reliable for identifying conflicts under imprecise and vague environments. The method allows the service design experts to freely and fully express their judgments, which better reflect group-oriented features of conflict identification. It will improve decision-making in PSO conflict identification. This research provides one of the first articles that introduce such a group decision making method based on unbalanced linguistic label set to identification of PSO design conflicts under vague judgment environment.

Another contribution of the work is that it develops a systematic and integrative process to identify and resolve PSO design conflicts, which is useful for practitioners in industry. While other researches in past literature sporadically focus on conflict identification or resolution, for example, in Chai et al. (2005), the researchers only provide conflict resolving method directly based on TRIZ without specific conflict analysis and identification method and process. On the contrary, this research not only presents a systematic process but also provides supporting methods including SFAA, 
group-oriented conflict identification, and conflict resolving approaches. Further, the proposed method takes into account practice in industry for example of conflict identification, and thus has high potential for usage by industry.

\section{Conclusions}

In order to identify and solve the conflicts of service technical attributes in PSO design, this study introduced a systematic approach based on the Service Function and Attribute Analysis (SFAA), group decision making with unbalanced linguistic label set and TRIZ methodology. The method of SFAA is firstly proposed to elicit the PSO functions and technical attributes. Then, group decision making based on unbalanced linguistic label set is utilized to identify the potential conflicts between PSO technical attributes. The contradiction matrix and inventive principles in TRIZ methodology is then introduced to resolve the conflicts between PSO technical attributes. A case study of conflict resolution in elevator service design shows that the proposed approach is feasible and can be easily implemented.

Although the proposed method demonstrates potentials in conflict identification and resolution of PSO technical attributes, it still has some more research to be conducted in the future. Future research may focus on developing a more comprehensive conflict resolving approach incorporating more TRIZ tools, e.g. STEPS software (Systematic Tool for Efficient Problem Solving) (Chinkatham and Cavallucci 2015). In addition, more external testing work is necessary to obtain even higher validity of the method.

\section{Acknowledgments}

\section{References}

Arai, T., \& Shimomura, Y. (2004). Proposal of service CAD system-a tool for service engineering. CIRP Annals-Manufacturing Technology, 53(1), 397-400.

Aurich, J. C., Fuchs, C., \& Wagenknecht, C. (2006). Life cycle oriented design of technical Product-Service Systems. Journal of Cleaner Production,14(17), 14801494.

Baines, T. S., Lightfoot, H. W., Benedettini, O., \& Kay, J. M. (2009). The servitization of manufacturing: A review of literature and reflection on future challenges. Journal of Manufacturing Technology Management, 20(5), 547-567.

Blackhurst, J., Wu, T. T., \& Craighead, C. W. (2008). A systematic approach for supply chain conflict detection with a hierarchical Petri Net extension.Omega, 36(5), 680696.

Cavallucci, D., Rousselot, F., \& Zanni, C. (2009). Assisting R\&D activities definitionthrough problem mapping. CIRP Journal of Manufacturing Science and Technology, 1(3), 131-136.

Cavallucci, D., Rousselot, F., \& Zanni, C. (2011). On contradiction clouds. Procedia Engineering, 9, 368-378.

Ceroni, J. A., \& Velásquez, A. A. (2003). Conflict detection and resolution in distributed design. Production Planning \& Control, 14(8), 734-742. 
Chen, X. W., \& Nof, S. Y. (2010). A decentralised conflict and error detection and prediction model. International Journal of Production Research, 48(16), 4829-4843. Chai, K. H., Zhang, J., \& Tan, K. C. (2005). A TRIZ-based method for new service design. Journal of Service Research, 8(1), 48-66.

Chang, H. T., \& Chen, J. L. (2004). The conflict-problem-solving CAD software integrating TRIZ into eco-innovation. Advances in Engineering Software, 35(8), 553-566.

Chinkatham, T., \& Cavallucci, D. (2015). On Solution Concept Evaluation/Selection in Inventive Design. Procedia Engineering, 131, 1073-1083.

Domb, E., \& Mann, D. (1999). 40 Inventive (Business) Principles with Examples. The TRIZ Journal, http://www. triz-journal. com.

Geng, X., Chu, X., Xue, D., \& Zhang, Z. (2010). An integrated approach for rating engineering characteristics' final importance in product-service system development. Computers \& Industrial Engineering, 59(4), 585-594.

Hisarciklilar, O., Rahmani, K., \& Thomson, V. (2010, January). A conflict detection approach for collaborative management of product interfaces. In ASME 2010 International Design Engineering Technical Conferences and Computers and Information in Engineering Conference (pp. 555-563). American Society of Mechanical Engineers.

Houssin, R., \& Coulibaly, A. (2011). An approach to solve contradiction problems for the safety integration in innovative design process. Computers in Industry,62(4), 398-406.

Houssin, R., Renaud, J., Coulibaly, A., Cavallucci, D., \& Rousselot, F. (2015). TRIZ theory and case based reasoning: synergies and oppositions. International Journal on Interactive Design and Manufacturing (IJIDeM), 9(3), 177-183.

Jiang, T., \& Nevill, G. E. (2002). Conflict cause identification in web-based concurrent engineering design system. Concurrent Engineering, 10(1), 15-25.

Kim, S., \& Yoon, B. (2012). Developing a process of concept generation for new product-service systems: a QFD and TRIZ-based approach. Service Business, 6(3), 323-348.

Kim, Y. S., Shin, D. H., Jeon, H. B., Lee, K. H., Cho, K. S., \& Park, W. (2013). Conflict detection in composite web services based on model checking. International Journal of Web and Grid Services, 9(4), 394-430.

Klein, M. (2000). Towards a systematic repository of knowledge about managing collaborative design conflicts (pp. 129-146). Springer Netherlands.

Krause, F. L., Kiesewetter, T., \& Kramer, S. (1994). Distributed product design. CIRP Annals-Manufacturing Technology, 43(1), 149-152.

Lara, M. A., \& Nof, S. Y. (2003). Computer-supported conflict resolution for collaborative facility designers. International Journal of Production Research,41(2), 207-233.

Lee, K. H., \& Lee, K. Y. (2005). Case-based conflict resolution in multi-agent ship design system. In AI 2005: Advances in Artificial Intelligence (pp. 826-829). Springer Berlin Heidelberg.

Lee, S., Han, W., \& Park, Y. (2015). Measuring the functional dynamics of product- 
service system: A system dynamics approach. Computers \& Industrial Engineering, 80, 159-170.

Li, X., Zhou, X., \& Ruan, X. (2002). Conflict management in closely coupled collaborative design system. International Journal of Computer Integrated Manufacturing, 15(4), 345-352.

Malakooti, B. (2012). Decision making process: typology, intelligence, and optimization. Journal of intelligent manufacturing, 23(3), 733-746.

Maussang, N., Zwolinski, P., \& Brissaud, D. (2009). Product-service system design methodology: from the PSS architecture design to the products specifications. Journal of Engineering Design, 20(4), 349-366.

Rovida, E., Bertoni, M., \& Carulli, M. (2009). About the use of TRIZ for productservice development. In DS 58-1: Proceedings of ICED 09, the 17th International Conference on Engineering Design, Vol. 1, Design Processes, Palo Alto, CA, USA, 24.-27.08. 2009.

Ruchti, B., \& Livotov, P. (2001). TRIZ-based innovation principles and a process for problem solving in business and management. The TRIZ Journal,1, 677-687.

Sakao, T., Fargnoli M. (2010). Customization in Ecodesign: A Demand-side Approach Bringing New Opportunities? J. Ind. Ecol. 14(4), 529 - 532.

Sakao, T., \& Shimomura, Y. (2007). Service Engineering: a novel engineering discipline for producers to increase value combining service and product. Journal of Cleaner Production, 15(6), 590-604.

Sakao, T. (2007). A QFD-centred design methodology for environmentally conscious product design. International Journal of Production Research,45(18-19), 4143-4162.

Sakao, T., Shimomura, Y., Sundin, E., \& Comstock, M. (2009). Modeling design objects in CAD system for service/product engineering. Computer-Aided Design, 41(3), 197-213.

Shimomura, Y., \& Hara, T. (2010). Method for supporting conflict resolution for efficient PSS development. CIRP Annals-Manufacturing Technology,59(1), 191-194.

Song, W., \& Chan, F. T. (2015a). Multi-objective configuration optimization for product-extension service. Journal of Manufacturing Systems, 37, 113-125.

Song, W., Ming, X., Han, Y., Xu, Z., \& Wu, Z. (2015b). An integrative framework for innovation management of product-service system. International Journal of Production Research, 53(8), 2252-2268.

Song, W., Wu, Z., Li, X., \& Xu, Z. (2015c). Modularizing product extension services: An approach based on modified service blueprint and fuzzy graph.Computers \& Industrial Engineering, 85, 186-195.

Ostrosi, E., Haxhiaj, L., \& Fukuda, S. (2012). Fuzzy modelling of consensus during design conflict resolution. Research in Engineering Design, 23(1), 53-70.

Ouertani, M. Z. (2008). Supporting conflict management in collaborative design: an approach to assess engineering change impacts. Computers in Industry, 59(9), 882893.

Váncza, J., Monostori, L., Lutters, D., Kumara, S. R., Tseng, M., Valckenaers, P., \& Van Brussel, H. (2011). Cooperative and responsive manufacturing enterprises. CIRP Annals-Manufacturing Technology, 60(2), 797-820. 
Velasquez, J. D., Lara, M. A., \& Nof, S. Y. (2008). Systematic resolution of conflict situations in collaborative facility design. International Journal of Production Economics, 116(1), 139-153.

Vera, A., Kvan, T., West, R., \& Lai, S. (1998). Expertise and collaborative design. CHI '98 Conference Proceedings, CHI '98, ACM, Los Angeles, 1998, pp. 503 - 510.

Wu, Z., \& Chen, Y. (2007). The maximizing deviation method for group multiple attribute decision making under linguistic environment. Fuzzy Sets and Systems, 158(14), 1608-1617.

$\mathrm{Xu}, \mathrm{Z}$. (2009). An interactive approach to multiple attribute group decision making with multigranular uncertain linguistic information.Group Decision and Negotiation, 18(2), 119-145.

Yan, B. (2013). A Systematic Study of Design Conflict: Modeling, Representation, Resolution, and Application (Doctoral dissertation, Concordia University).

Yan, B., \& Zeng, Y. (2011). Design conflict: conceptual structure and mathematical representation. Journal of Integrated Design and Process Science, 15(1), 75.

Yang, L., \& Xing, K. (2013, July). Innovative conceptual design approach for product service system based on TRIZ. In Service Systems and Service Management (ICSSSM), 2013 10th International Conference on (pp. 247-252). IEEE.

Yang, X., Moore, P., Pu, J. S., \& Wong, C. B. (2009). A practical methodology for realizing product service systems for consumer products. Computers \& Industrial Engineering, 56(1), 224-235.

Zhang, J., Tan, K. C., \& Chai, K. H. (2003). Systematic innovation in service design through TRIZ. The TRIZ Journal, 9.

Zhao, Y., Hong, H., Wang, H., Chen, W., Wang, H., \& Jie, J. (2013). Conflict Coordination Based on the Transformation Bridge for Collaborative Product Performance Optimization. In Cooperative Design, Visualization, and Engineering (pp. 111-119). Springer Berlin Heidelberg. 
Table1

\section{Tables List}

Technical attributes ofelevator service

\begin{tabular}{llll} 
NO. & \multicolumn{1}{c}{ Technical attributes } & NO. & \multicolumn{1}{c}{ Technical attributes } \\
$\mathrm{TA}_{1}$ & Professional configuration proposal & $\mathrm{TA}_{7}$ & Repair level \\
$\mathrm{TA}_{2}$ & Fast \& professional installation & $\mathrm{TA}_{8}$ & Cost of spare parts replacement \\
$\mathrm{TA}_{3}$ & Coverage of condition monitoring & $\mathrm{TA}_{9}$ & Coverage of service network \\
$\mathrm{TA}_{4}$ & Accuracy of failure diagnosis & $\mathrm{TA}_{10}$ & Short time of service dispatching \\
$\mathrm{TA}_{5}$ & Professional and timely & $\mathrm{TA}_{11}$ & Availability of 7d $\times$ 24h emergency \\
& maintenance & & repair \\
$\mathrm{TA}_{6}$ & Elevator operation training & $\mathrm{TA}_{12}$ & Retrofit \& upgrade \\
\hline
\end{tabular}

Table 2

The linguistic judgments on the relationships between TAs of elevator service

$\begin{array}{llllll}\text { Pair of technical attributes } & \text { Expert } 1 & \text { Expert } 2 & \text { Expert } 3 & \text { Expert } 4 & \text { Expert } 5\end{array}$

\begin{tabular}{cccccc}
$\mathrm{TA}_{1}-\mathrm{TA}_{2}$ & {$\left[S_{-1 / 2}^{(4)}, S_{0}^{(4)}\right]$} & $S_{3}^{(4)}$ & $S_{-1}^{(5)}$ & {$\left[S_{-2}^{(3)}, S_{0}^{(3)}\right]$} & $S_{1 / 2}^{(4)}$ \\
$\mathrm{TA}_{3}-\mathrm{TA}_{4}$ & {$\left[S_{-4 / 3}^{(4)}, S_{-1 / 2}^{(4)}\right]$} & $S_{-3}^{(4)}$ & $S_{-2}^{(5)}$ & {$\left[S_{-2 / 3}^{(3)}, S_{0}^{(3)}\right]$} & $S_{-4 / 3}^{(4)}$ \\
$\mathrm{TA}_{9}-\mathrm{TA}_{10}$ & {$\left[S_{-4 / 3}^{(4)}, S_{0}^{(4)}\right]$} & $S_{-3}^{(4)}$ & $S_{-2}^{(5)}$ & {$\left[S_{-2}^{(3)}, S_{-2 / 3}^{(3)}\right]$} & $S_{-4 / 3}^{(4)}$ \\
\hline
\end{tabular}

Table 3

The unified linguistic judgments on the relationships between TAs

$\begin{array}{llllll}\text { Pair of technical attributes } & \text { Expert } 1 & \text { Expert } 2 & \text { Expert } 3 & \text { Expert } 4 & \text { Expert } 5\end{array}$

$\begin{array}{cccccc}\mathrm{TA}_{1}-\mathrm{TA}_{2} & {\left[S_{-1 / 2}^{(4)}, S_{0}^{(4)}\right]} & S_{3}^{(4)} & S_{-3 / 4}^{(4)} & {\left[S_{-3}^{(4)}, S_{0}^{(4)}\right]} & S_{1 / 2}^{(4)} \\ \mathrm{TA}_{3}-\mathrm{TA}_{4} & {\left[S_{-4 / 3}^{(4)}, S_{-1 / 2}^{(4)}\right]} & S_{-3}^{(4)} & S_{-3 / 2}^{(4)} & {\left[S_{-1}^{(4)}, S_{0}^{(4)}\right]} & S_{-4 / 3}^{(4)} \\ \mathrm{TA}_{9}-\mathrm{TA}_{10} & {\left[S_{-4 / 3}^{(4)}, S_{0}^{(4)}\right]} & S_{-3}^{(4)} & S_{-3 / 2}^{(4)} & {\left[S_{-3}^{(4)}, S_{-1}^{(4)}\right]} & S_{-4 / 3}^{(4)}\end{array}$

Table 4

The unified linguistic judgments and indication value of conflict

\begin{tabular}{ccccccc}
$\begin{array}{c}\text { Pair of } \\
\text { technical } \\
\text { attributes }\end{array}$ & Expert 1 & $\begin{array}{c}\text { Expert } \\
2\end{array}$ & $\begin{array}{c}\text { Expert } \\
3\end{array}$ & $\begin{array}{c}\text { Expert } \\
4\end{array}$ & $\begin{array}{c}\text { Expert } \\
5\end{array}$ & $\begin{array}{c}\text { Indication value of } \\
\text { conflict }\end{array}$ \\
\hline $\mathrm{TA}_{1}-\mathrm{TA}_{2}$ & $S_{-1 / 4}^{(4)}$ & $S_{3}^{(4)}$ & $S_{-3 / 4}^{(4)}$ & $S_{-3 / 2}^{(4)}$ & $S_{1 / 2}^{(4)}$ & $S_{0.2}^{(4)}$ \\
$\mathrm{TA}_{3}-\mathrm{TA}_{4}$ & $S_{-0.917}^{(4)}$ & $S_{-3}^{(4)}$ & $S_{-3 / 2}^{(4)}$ & $S_{-0.5}^{(4)}$ & $S_{-4 / 3}^{(4)}$ & $S_{-1.45}^{(4)}$ \\
$\mathrm{TA}_{9}-\mathrm{TA}_{10}$ & $S_{-2 / 3}^{(4)}$ & $S_{-3}^{(4)}$ & $S_{-3 / 2}^{(4)}$ & $S_{-2}^{(4)}$ & $S_{-4 / 3}^{(4)}$ & $S_{-1.7}^{4}$ \\
\hline
\end{tabular}




\section{Table5}

The recommended principles for resolving TA' conflicts of elevator service

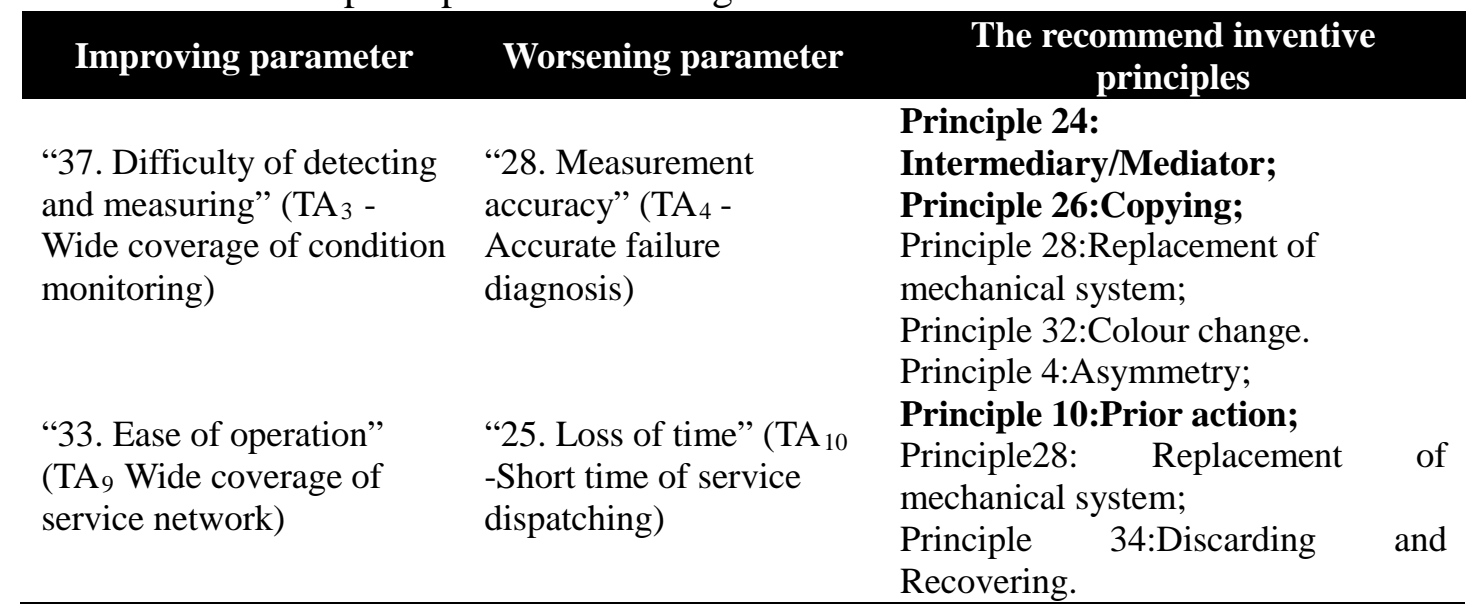




\section{Figures List}

PSO function \& technical attribute analysis

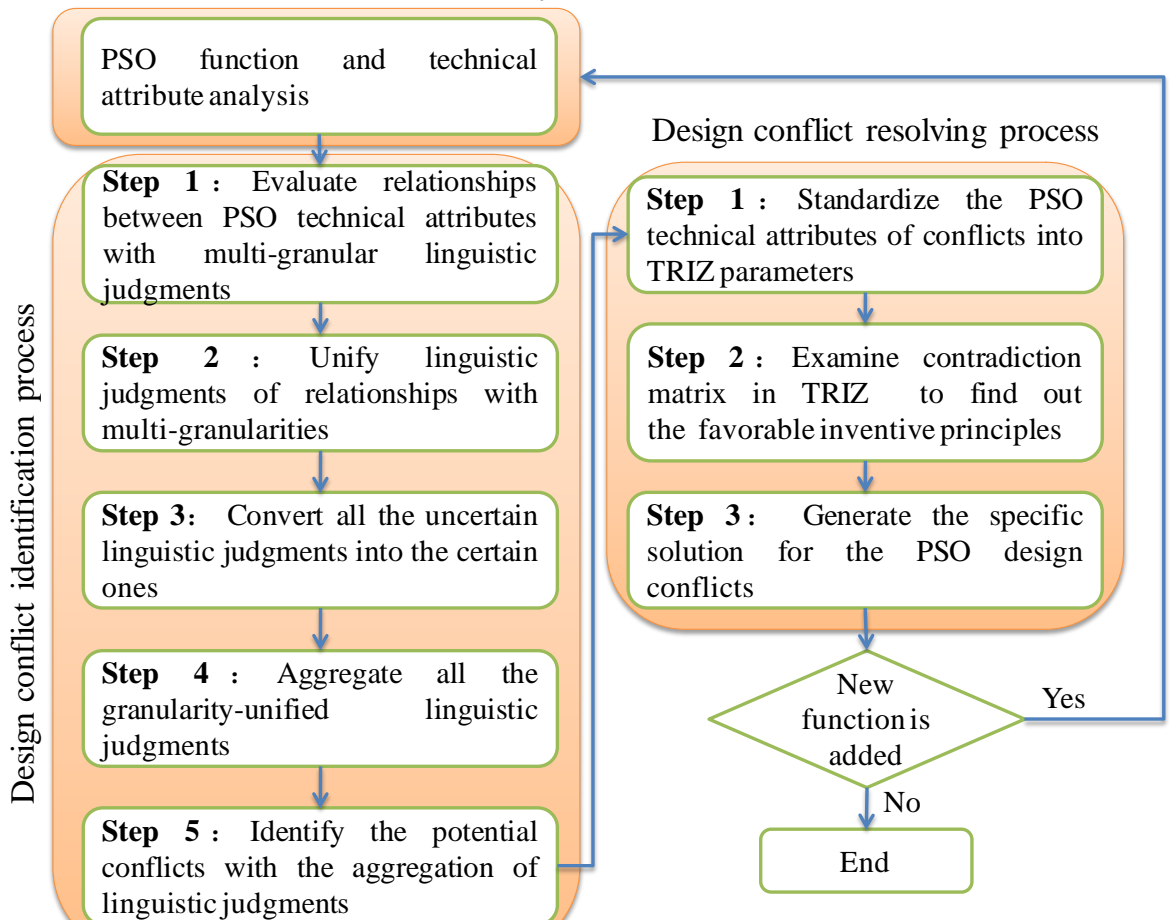

Figure1 Technical attributes’ conflict resolution process

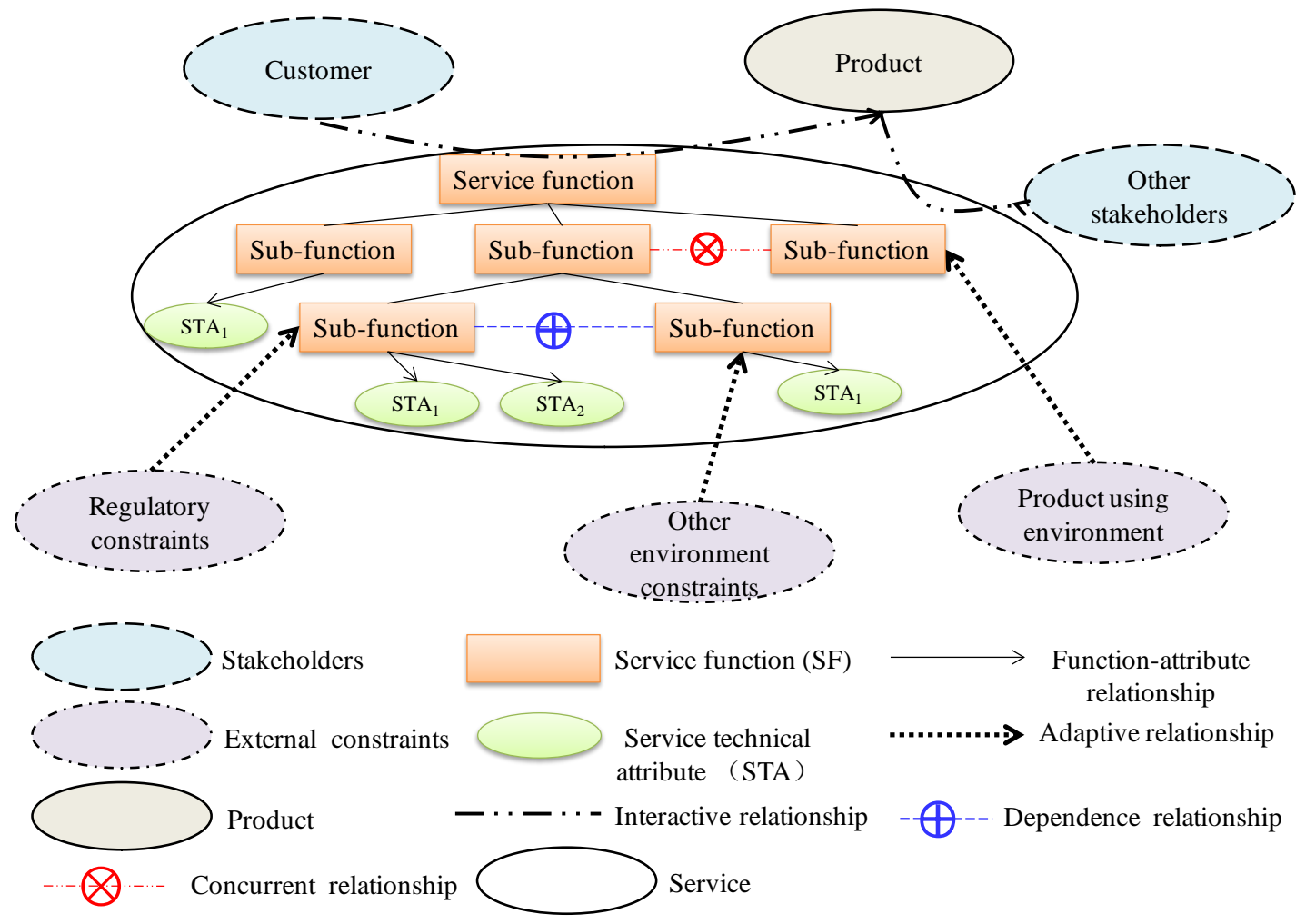

Figure2 Service Function and Attribute Analysis (SFAA) 


$\begin{aligned} & \text { Strong } \\ & \text { conflict }\end{aligned}$
$S_{-3}^{(4)}$

Figure 3Linguistic label set $\mathrm{S}^{(4)}$ with granularity of 7

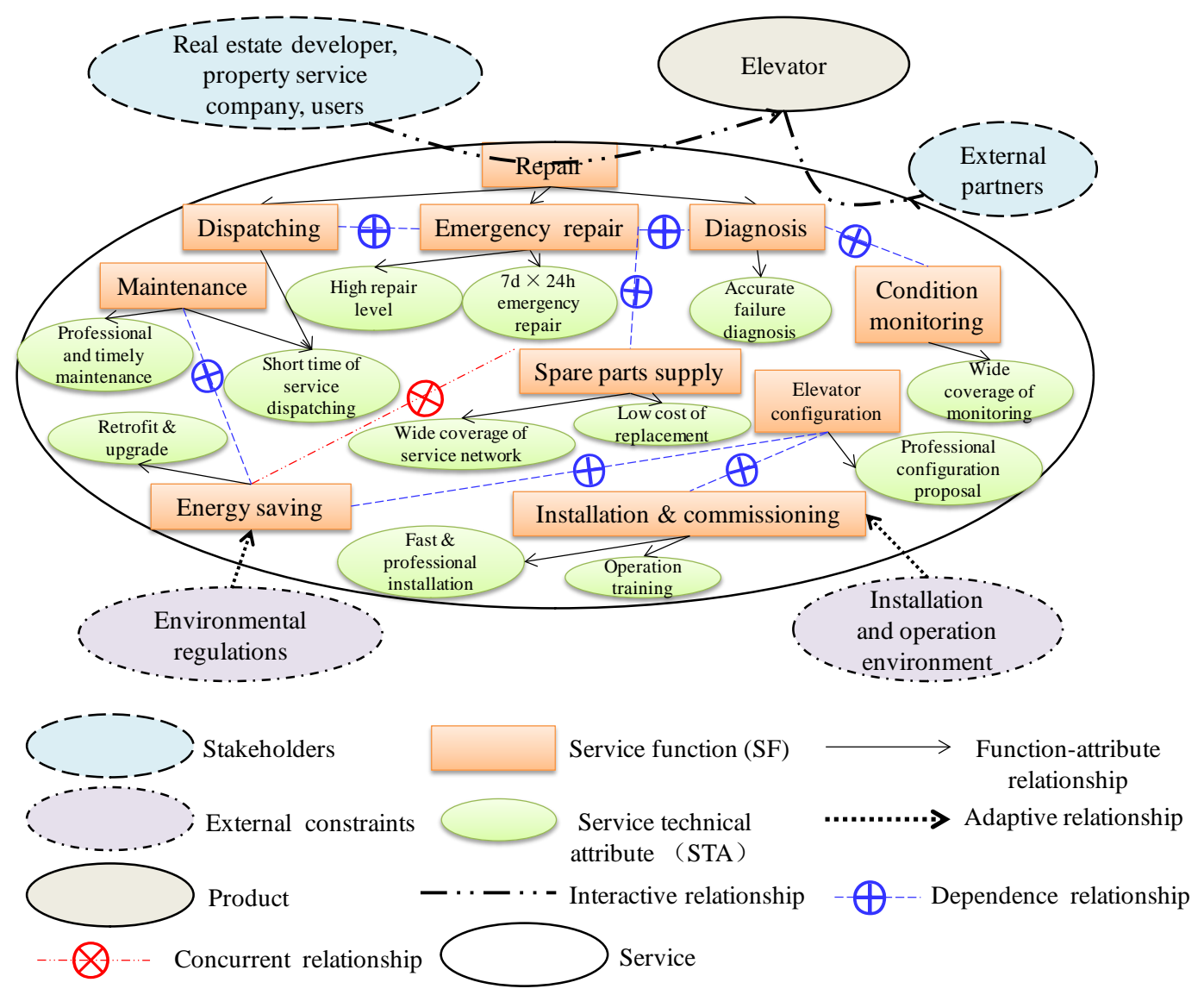

Figure4 Service function and attribute analysis of elevator PSO

Note: Some relationships are omitted in the figure to simplify the description yet maintaining the essence for the method verification. 